\title{
JUURNAL
}

of Health Inequalities

\section{Prevalence of tobacco smoking among participants of PURE Poland study}

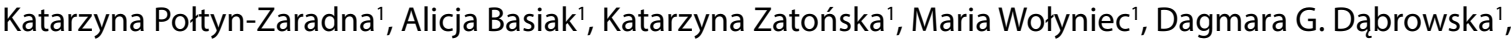 \\ Andrzej Szuba², Witold A. Zatoński3i,4 \\ 'Department of Social Medicine, Wroclaw Medical University, Wroclaw, Poland \\ 2Division of Angiology, Wroclaw Medical University \& Department of Internal Medicine, $4^{\text {th }}$ Military Hospital in Wroclaw, \\ Poland \\ ${ }^{3}$ Health Promotion Foundation, Nadarzyn, Poland \\ ${ }^{4}$ Higher Vocational State School in Kalisz, Poland
}

\begin{abstract}
Introduction: Smoking is the largest avoidable health risk factor in Europe. The aim of this paper is to assess the attitude towards tobacco smoking among participants of PURE Poland Study.

Material and methods: Analysis of attitude towards tobacco smoking was carried out between 2007 and 2010 in a cohort consisting of 2,036 subjects aged from 30 to 85, living in Wroclaw and surrounding municipalities, enrolled in the PURE (Prospective Urban and Rural Epidemiological) Study. We analyzed percentage of current smokers, ex-smokers, and never smokers in the study population. The collected data was analyzed according to sex, age, place of residence, and education. The significance level was $p \leq 0.05$.

Results: Among surveyed, 21.0\% were current smokers, $31.7 \%$ were ex-smokers, and $47.3 \%$ have never smoked. $26.4 \%$ of rural population were current smokers, while in urban population it was only $17.2 \%$. Place of residence in the rural area increases the risk of being a current smoker 1.7-fold (OR $=1.7269$, CI 1.3924 to 2.1418); on the other hand, living in an urban area, increases the chance of quitting smoking 2.3 -fold ( $\mathrm{OR}=2.3044$, CI 1.7897 to 2.9671$) .15 .1 \%$ of people with higher education were current smokers in comparison to $30.2 \%$ with vocational education. Men have taken on smoking significantly earlier (19.2 $\mathrm{SD} \pm 4.6)$ than women $(20.4 \mathrm{SD} \pm 4.4)$, and smoked more cigarettes a day than women (17.5 cigarette a day $\mathrm{SD} \pm 9.1$ vs. 13.1 cigarette a day $\mathrm{SD} \pm 9.0)$.

Conclusions: The percentage of current smokers is much higher among rural than urban dwellers. Recently, more people quit smoking in urban than rural areas.
\end{abstract}

KEY WORDS: tobacco, urban, rural, PURE study.

\section{KEY FINDINGS}

1. The percentage of current smokers is much higher among rural than urban dwellers.

2. Place of residence (rural) became more significant differentiating factor of smoking than sex, unlike several decades ago.

3. Recently, more people quit smoking in urban than rural areas.

4. The percentage of current smokers is the highest among the youngest age group (30-44 years)

5. Age of initiation of smoking depends on birth cohort (initiation is earlier along with decreasing age of study population).

6. Women initiate smoking later than men 


\section{INTRODUCTION}

According to the European Commission, smoking is the largest avoidable health risk factor in Europe, causing more problems than alcohol, drugs, high blood pressure, excessive weight, or high cholesterol put together [1]. Every year, nearly 700,000 Europeans die prematurely of tobacco-related diseases. It is estimated that in terms of economic impact, smoking costs the EU countries at least $€ 100$ billion per year [1]. Tobacco smoking is a major avoidable single cause of premature mortality in Poland. Almost one in three Polish men do not live to the age of 65 , and almost half of this premature mortality can be associated with much higher prevalence of smoking in Poland than in Western Europe [2]. According to EU data from 2012, 32.0\% of Poles were current smokers in comparison to $28.0 \%$ of other EU citizens [1]. The percentage of smoking women in Poland was $24.4 \%$ and smoking men $36.9 \%$ [3]. According to WHO's report on the current status of the tobacco epidemic in Poland, the average financial cost of premature death is estimated at 621,000 PLN per person, averaging 5,5 billion PLN for over 8,000 premature deaths from second-hand smoke recorded in 2002 [4]. Because Poles are exposed to tobacco smoke for an average of 20 years, this cost might even reach 135 billion PLN in the next 20 years [5]. Attitudes toward smoking are differentiated by sex, place of residence (urban-rural), age, and education [3-7].

The aim of this paper is to evaluate the attitude towards tobacco smoking among PURE study participants, emphasizing the place of residence (urban - rural).

\section{MATERIAL AND METHODS}

PURE (Prospective Urban Rural Epidemiology) study covers 21 countries of different status of economic development, and enrolls overall of 150,000 people [8]. All participants were tested in accordance to the PURE project protocol. The paper presents results of PURE Poland study - baseline, covering group of 2,036 people divided into three age groups $(<45,45-64,>64$ years old), 1,277 women and 758 men inhabitants of both urban and rural areas from Lower Silesia. The study was conducted between 2007-2010. During the study, all partakers after $3,6,9$, and 12 years of project cycle have been invited for follow-up.

Participants were considered ever smokers if they reported smoking at least one cigarette per day for at least one year. Ever smokers were divided into current smokers (do you currently smoke cigarettes?) and ex-smokers (if they had stopped smoking before the survey). We also recorded the duration of smoking in years and age of smoking initiation.

Data collected was analyzed with use of Statistica 12.0 PL computer programme, with sex, age, place of residence, and education considered. The significance level was established as $p \leq 0.05$.

\section{RESULTS}

Among surveyed, $21.0 \%$ were current smokers, $31.7 \%$ were ex-smokers, and $47.3 \%$ have never smoked. Attitude towards tobacco smoking in PURE study population was statistically significantly differentiated by sex, age, place of residence, and education level (Table 1).

TABLE 1. General characteristics of tobacco smoking among participants of PURE Poland study

\begin{tabular}{|c|c|c|c|c|c|c|}
\hline \multirow[t]{2}{*}{ Characteristics } & \multicolumn{3}{|c|}{ Ever smokers } & \multirow{2}{*}{$\begin{array}{c}\text { Never } \\
\text { smokers }\end{array}$} & \multirow[t]{2}{*}{$P$-value* } & \multirow[t]{2}{*}{$P$-value ${ }^{* *}$} \\
\hline & Current smokers & Ex-smokers & Total & & & \\
\hline Total & $425(21.0)$ & $644(31.7)$ & $1,069(52.7)$ & $961(47.3)$ & & \\
\hline \multicolumn{7}{|l|}{ Sex } \\
\hline Men & $180(24.0)$ & $310(41.3)$ & $490(65.3)$ & $261(34.7)$ & \multirow[t]{2}{*}{0.000} & \multirow[t]{2}{*}{0.000} \\
\hline Women & $245(19.2)$ & $334(26.1)$ & $579(45.3)$ & $700(54.7)$ & & \\
\hline \multicolumn{7}{|l|}{ Age group } \\
\hline $30-44$ & $86(24.2)$ & $84(23.7)$ & $170(47.9)$ & $185(52.1)$ & \multirow[t]{3}{*}{0.000} & \multirow[t]{3}{*}{0.00001} \\
\hline $45-64$ & $317(23.5)$ & $454(33.7)$ & $771(57.2)$ & $578(42.8)$ & & \\
\hline$>64$ & $22(6.7)$ & $106(32.5)$ & $128(39.2)$ & $198(60.8)$ & & \\
\hline \multicolumn{7}{|c|}{ Place of residence } \\
\hline Urban & $207(17.2)$ & $442(36.7)$ & 649 (53.9) & $555(46.1)$ & \multirow[t]{2}{*}{0.000} & \multirow[t]{2}{*}{0.18} \\
\hline Rural & $218(26.4)$ & $202(24.5)$ & $420(50.9)$ & $406(49.1)$ & & \\
\hline \multicolumn{7}{|c|}{ Level of education } \\
\hline Primary & $61(20.2)$ & $75(24.8)$ & $136(45.0)$ & $166(55.0)$ & \multirow[t]{4}{*}{0.002} & \multirow[t]{4}{*}{0.0001} \\
\hline Vocational & $98(30.2)$ & $92(28.4)$ & $190(58.6)$ & $134(41.4)$ & & \\
\hline Secondary & $175(22.0)$ & $284(35.7)$ & $459(57.7)$ & $337(42.3)$ & & \\
\hline Higher & $91(15.1)$ & $192(31.8)$ & $283(46.9)$ & $320(53.1)$ & & \\
\hline
\end{tabular}

*between current smokers, ex-smokers and never smokers; **between ever smokers and never smokers 
TABLE 2. Number of cigarettes smoked daily among ever smoking $(1,069)$ participants of PURE Poland study

\begin{tabular}{|c|c|c|c|c|c|}
\hline Characteristics & Average number & Minimum & Maximum & SD & $P$-value \\
\hline Total & 15.1 & 1.0 & 80.0 & 9.3 & \\
\hline \multicolumn{6}{|l|}{ Sex } \\
\hline Men & 16.3 & 1.0 & 60.0 & 8.7 & \multirow[t]{2}{*}{0.000000} \\
\hline Women & 13.1 & 1.0 & 80.0 & 9.0 & \\
\hline \multicolumn{6}{|l|}{ Age group } \\
\hline $30-44$ & 13.1 & 1.0 & 40.0 & 8.1 & \multirow[t]{3}{*}{0.000063} \\
\hline $45-64$ & 15.1 & 1.0 & 80.0 & 9.2 & \\
\hline$>64$ & 17.7 & 1.0 & 60.0 & 10.4 & \\
\hline \multicolumn{6}{|c|}{ Place of residence } \\
\hline Urban & 14.2 & 1.0 & 60.0 & 8.6 & \multirow[t]{2}{*}{0.000063} \\
\hline Rural & 16.5 & 1.0 & 80.0 & 10.1 & \\
\hline \multicolumn{6}{|c|}{ Level of education } \\
\hline Primary & 17.5 & 1.0 & 60.0 & 8.9 & \multirow[t]{4}{*}{0.000004} \\
\hline Vocational & 17.1 & 1.0 & 80.0 & 10.6 & \\
\hline Secondary & 14.5 & 1.0 & 60.0 & 9.1 & \\
\hline Higher & 13.5 & 1.0 & 40.0 & 8.3 & \\
\hline
\end{tabular}

$19.2 \%$ of women were current smokers, in comparison to $24.0 \%$ of men. Gender is risk factor of smoking; men are 1,3-fold more likely to be current smokers than women $(\mathrm{OR}=1.3304, \mathrm{CI} 1.0700$ to 1.6543$)$. With the increase of age, the number of current smokers decreases proportionally: $24.2 \%$ of current smokers aged $30-44,23.5 \%$ of current smokers aged $45-64$, and $6.8 \%$ of current smokers aged over 64 years. $26.4 \%$ of rural population were current smokers, while in urban population it was only $17.2 \% .15 .1 \%$ of participants with higher education were current smokers, in comparison to $30.2 \%$ with vocational education.

Average number of cigarettes smoked daily was 15.1 cigarette a day, $\mathrm{SD} \pm 9.3$ (Table 2). Men were smoking relatively more: 17.5 cigarette a day, $\mathrm{SD} \pm 9.1$ than women: 13.1 cigarette a day $S D \pm 9.0$. Rural area's population was smoking relatively more: 16.5 cigarette a day, $\mathrm{SD} \pm 10.1$ than of urban area: 14.2 cigarette a day, $S D \pm 8.6$. With the increase of educational level, the average number of cigarettes smoked daily decreases (17.5 cigarette a day, $\mathrm{SD} \pm 8.9$ in primary education group vs. 13.5 cigarette a day, $\mathrm{SD} \pm 8.3$ in higher education group).

Average age of initiation of smoking in studied population was $19.8, \mathrm{SD} \pm 4.5$ (Table 3). Men have taken on smoking significantly earlier $(19.2, \mathrm{SD} \pm 4.6)$ than women $(20.4, \mathrm{SD} \pm 4.4)$. With decreasing age of the participants observed, the average age of initiation of smoking decreases $(21.1 \pm 6.7$ in group $>64$ years, $19.7 \pm 4.1$ in group $45-64$ years, and $19.4 \pm 3.9$ in group 30 - 44 years).
Urban participants have taken on smoking earlier (19.7, $\mathrm{SD} \pm 4.2)$ than rural $(20.1, \mathrm{SD} \pm 4.9)$. There were no statistically significant differences between the average age of initiation of smoking and level of education.

Place of residence in the rural area increases the risk of being a current smoker nearly 1.7-fold (OR = 1.7269, CI 1.3924 to 2.1418); on the other hand, living in urban area, increases the chance of quit smoking over 2.3-fold $(\mathrm{OR}=2.3044$, CI 1.7897 to 2.9671$)$. The detailed analysis of attitude towards tobacco smoking adjusted for sex, age, and place of residence has demonstrated that either men or women in every age group living in the urban area are characterised by lower percentage of current smokers and higher percentage of ex-smokers (Table 4). In men, statistically significant differences in percentage of current smokers was observed in group aged $30-44$ years (15.0\% of current smokers in urban vs. $39.7 \%$ in rural area). In women, statistically significant differences were observed in group aged $30-44$ years (14.9\% of current smokers in urban vs. $33.7 \%$ in rural area), and in group aged $45-64$ years $(18.9 \%$ of current smokers in urban vs. $26.0 \%$ in the rural area).

\section{DISCUSSION}

In our study, one-fifth of the population aged 30 years or more are current smokers. This result is consistent with the data obtained within Polish-Norwegian (PONS) Study conducted in years 2010-2011 among 
TABLE 3. Age of initiation of smoking among ever smoking $(1,069)$ participants of PURE Poland study

\begin{tabular}{|c|c|c|c|c|c|}
\hline Characteristics & Average age & Minimum & Maximum & SD & $P$-value \\
\hline Total & 19.8 & 6.0 & 50.0 & 4,5 & \\
\hline \multicolumn{6}{|l|}{ Sex } \\
\hline Men, total & 19.2 & 6.0 & 50.0 & 4.6 & \multirow[t]{2}{*}{0.000005} \\
\hline Women, total & 20.4 & 10.0 & 42.0 & 4.4 & \\
\hline \multicolumn{6}{|l|}{ Age groups* } \\
\hline $30-44$ & 19.4 & 10.0 & 41.0 & 3.9 & \multirow[t]{3}{*}{0.096993} \\
\hline $45-64$ & 19.7 & 6.0 & 42.0 & 4.1 & \\
\hline$>64$ & 21.1 & 12.0 & 50.0 & 6.7 & \\
\hline \multicolumn{6}{|c|}{ Place of residence } \\
\hline Urban & 19.7 & 6.0 & 42.0 & 4.2 & \multirow[t]{2}{*}{0.096993} \\
\hline Rural & 20.1 & 10.0 & 50.0 & 4.9 & \\
\hline \multicolumn{6}{|c|}{ Level of education } \\
\hline Primary & 19.7 & 10.0 & 50.0 & 5.7 & \multirow[t]{4}{*}{0.15} \\
\hline Vocational & 19.8 & 13.0 & 42.0 & 4.1 & \\
\hline Secondary & 19.9 & 8.0 & 47.0 & 4.2 & \\
\hline Higher & 19.9 & 6.0 & 48.0 & 4.7 & \\
\hline
\end{tabular}

TABLE 4. Characteristics of tobacco smoking among participants of PURE Poland study considering sex and place of residence (urban-rural)

\begin{tabular}{|c|c|c|c|c|c|c|c|c|c|}
\hline \multirow[t]{2}{*}{ Characteristics } & \multicolumn{3}{|c|}{ Current smoker } & \multicolumn{3}{|c|}{ Ex-smoker } & \multicolumn{3}{|c|}{ Never smoker } \\
\hline & Urban & Rural & $p$-values & Urban & Rural & $p$-values & Urban & Rural & $p$-values \\
\hline \multicolumn{10}{|l|}{ Men } \\
\hline \multicolumn{10}{|l|}{ Age group } \\
\hline $30-44$ & $14(15.0)$ & 25 (39.7) & 0.0005 & $25(26.9)$ & $15(23.8)$ & 0.0181 & $54(58.1)$ & $23(36.5)$ & 0.0082 \\
\hline $45-64$ & $65(22.6)$ & $62(34.3)$ & 0.060 & $147(51.2)$ & $63(30.9)$ & 0.00009 & $75(26.1)$ & $63(34.8)$ & 0.0451 \\
\hline$>64$ & $6(7.9)$ & $8(15.7)$ & 0.9007 & $39(51.3)$ & $28(54.9)$ & 0.29310 & $31(40.8)$ & $15(29.4)$ & 0.191 \\
\hline Total & $85(18.5)$ & $95(32.2)$ & 0.000 & $211(46.0)$ & 99 (33.6) & 0.00001 & $160(34.9)$ & $101(34.2)$ & 0.811 \\
\hline \multicolumn{10}{|l|}{ Women } \\
\hline \multicolumn{10}{|l|}{ Age group } \\
\hline $30-44$ & $16(14.9)$ & 31 (33.7) & 0.0019 & $20(18.7)$ & $24(26.1)$ & 0.2659 & $71(66.4)$ & $37(40.2)$ & 0.0001 \\
\hline $45-64$ & 103 (18.9) & $87(26.0)$ & 0.0128 & $184(33.7)$ & $67(20.0)$ & 0.00003 & 259 (47.4) & $181(54.0)$ & 0.05740 \\
\hline$>64$ & $3(3.2)$ & $5(4.8)$ & 0.5540 & $27(28.4)$ & $12(11.5)$ & 0.08886 & $65(68.4)$ & 87 (83.7) & 0.01150 \\
\hline Total & $122(16.3)$ & $123(23.2)$ & 0.002 & $231(30.9)$ & $103(19.4)$ & 0.000 & 395 (52.8) & 305 (57.4) & 0.10108 \\
\hline
\end{tabular}

dwellers of Świętokrzyskie voivodeship in Poland, aged 45-64 years - there were $20 \%$ of current smokers reported in that population [9]. The percentage of current smokers has decreased over the years (data obtained within HEM study in 2002 [10]), when $46 \%$ of men and $30.9 \%$ of women were current smokers. Polish arm of Global Tobacco Survey (GATS) from 2009-2010 has reported $36.9 \%$ of current smoking men and $24.4 \%$ of women [11]. Comparing our findings with data from major studies (Table 5), we can conclude that over the last decade, the percentage of current smokers had steadily decreased. 


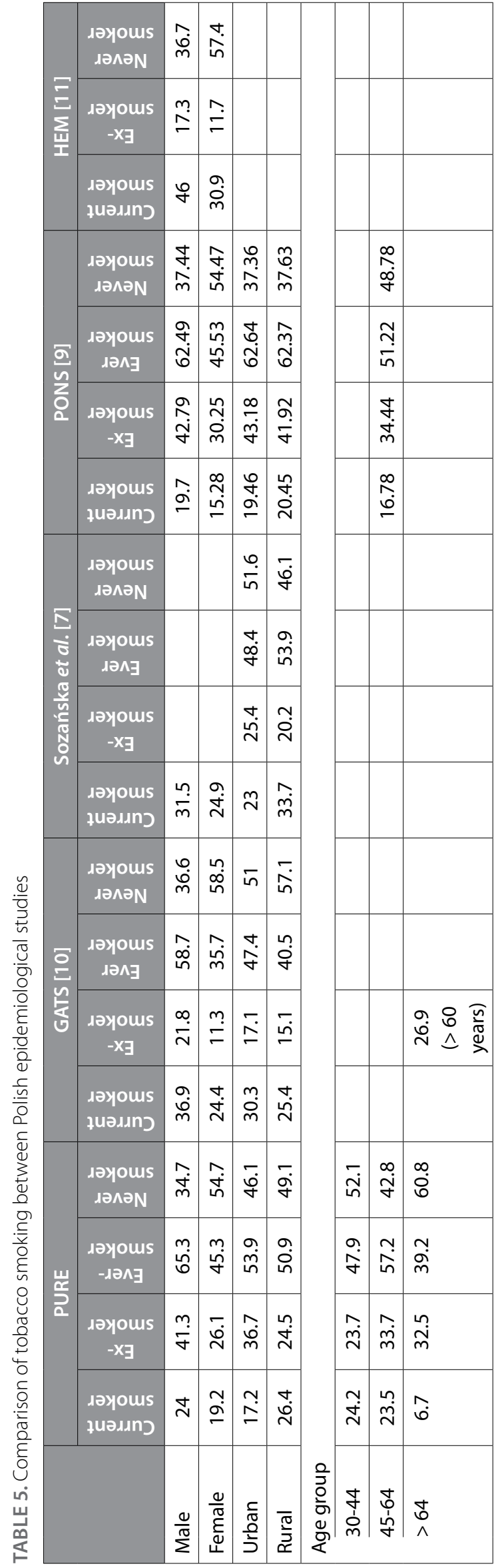

The strongly differentiating factor in the attitude towards tobacco smoking in our population was rural place of residence. Percentage of current smokers was much higher among rural than urban dwellers. Rural place of residence increases the risk of being a current smoker 1.7-fold. Those results are different from those obtained within GATS study that have reported higher percentage of current smokers among urban than rural dwellers ( $30.3 \%$ vs. $25.4 \%$, respectively), and the fact that the percentage of current smokers increased with urbanization of place of residence [11] (Table 5). Our results, in conjunction with data obtained by Sozańska et al. [7], who reported that the prevalence of current smokers was higher in rural population than in the population of a nearby small town, indicate that the trend observed in GATS study has been reversed. Lower percentage of current smokers reported in our study in both places of residence (17.2\% - Wroclaw agglomeration and $26.4 \%$ rural surroundings of Wroclaw) in comparison to study by Sozańska et al. obtained in 2012 (23.0\% - small town Sobótka and 33.7\% - rural surroundings of Sobótka) [7], can be an argument in favor of this conclusion. Likewise, in PONS study, the percentage of current smokers was higher among rural than urban dwellers, though the difference was not as significant as in our or Sozańska et al. study (Table 5). In addition, the chance of cessation of smoking is 2.3-fold higher among urban than rural dwellers (OR $=2.30$, CI 1.80 to 2.97 in PURE study and $\mathrm{OR}=2.37$, CI 1.32 to 4.25 in Sozańska et al. study). In our study, the percentage of smoking either men or women in every age group was higher among rural dwellers. What is alarming, the highest percentage of current smoking men and women was reported in the youngest age group of $30-44$ years $(39.7 \%$ of men and $33.7 \%$ of women, respectively). Among dwellers of rural surroundings of Sobótka, the highest percentage of current smokers was reported in the age group 51-60 years old - 44.9\%, and in the group 31-40 years old - 37.4\% [7]. On the other hand, among urban dwellers of Wrockaw, the highest percentage of current smokers was reported in the age group of $44-64$ (22.6\% of men and $18.9 \%$ of women, respectively). Among urban dwellers of Sobót$\mathrm{ka}$, the age group of 51-60 years old was characterised by highest percentage of current smokers; in the age group 31-40 years old, this percentage was $26.3 \%$ [7].

The average age of initiation of smoking among population of PURE study was 19.8 years old and it is statistically significantly higher among women than men (20.4 vs. 19.2). Those findings are consistent with the data obtained within GATS study, conducted in the population over 15 -years-old, which reported that in most cases, men and women started smoking at the age of 11-17 years old and 18-24 years old but women started smoking later than men [4]. In our population, we can observe a tendency of early initiation of smoking along with decrease of average age of smokers, but the 
age of initiation is higher among rural dwellers. Average number of smoked cigarettes in our study was lower than the amount reported in GATS study (15.1 cigarette a day vs. 17.2 cigarette a day, respectively). Rural dwellers smoke statistically significantly more than urban dwellers (urban: 14.2 cigarette a day in PURE; 17.0 cigarette a day in GATS and rural: 16.5 cigarette a day in PURE; 17.4 cigarette a day in GATS).

Clear confirmation of thesis underlying this article requires further research. An individual approach is essential while designing programmes of tobacco control, with special consideration to rural place of residence.

\section{DISCLOSURE}

Authors report no conflict of interest.

\section{References}

1. Attitudes of Europeans towards tobacco. Special Eurobarometer 429, European Commission, May 2015.

2. Zatoński W, Zatoński M, Przewoźniak K. Health improvement in Poland is contingent on continued extensive tobacco control measures. Ann Agric Environ Med 2013; 20: 405-411.

3. The current status of the tobacco epidemic in Poland. WHO Report 2009. Available from: http://www.euro.who.int/_data/assets/pdf_ file/0006/68064/E92470.pdf (accessed: 15 December 2016).

4. Kaleta D, Bukola U, Biliński P, et al. Global Adult Tobacco Survey (GATS) in Poland 2009-2010 - study strengths, limitations and lessons learned. Ann Agric Environ Med 2012; 19: 717-722.

5. Ministry of Health of Poland. Global adult tobacco survey. Poland 2009-2010. Warsaw: Ministry of Health 2010.

6. Giovino GA, Mirza SA, Samet JM, et al. Tobacco use in 3 billion individuals from 16 countries: an analysis of nationally representative cross-sectional household surveys. Lancet 2012; 380: 668-679.

7. Sozańska B, Pearce N, Błaszczyk M, et al. Changes in the prevalence of cigarette smoking and quitting smoking determinants in adult inhabitants of rural areas in Poland between 2003 and 2013. Public Health 2016; 141: 178-184.

8. Koon T, Chow C, Vaz M. The Prospective Urban Rural Epidemiology (PURE) study: Examining the impact of societal influences on chronic noncommunicable diseases in low-, middle-, and high-income countries. Am Heart J 2009; 158: 1-7.

9. Manczuk M, Boffetta P, Sartori S, et al. Cohort Profile: The PolishNorwegian Study (PONS) cohort. Int J Epidemiol 2015; 1-9: 1-5.

10. Zatoński W, Przewoźniak K. Tobacco Smoking in Countries of the European Union. Ann Agric Environ Med 2012; 19: 181-192.

11. Włodarczyk A, Raciborski F, Opoczyńska D, Samoliński B. Daily tobacco smoking patterns in rural and urban areas of Poland the results of the GATS study. Ann Agric Environ Med 2013; 20: 588-594.

\section{AUTHORS' CONTRIBUTIONS}

$K P Z, K Z$ and AS prepared research concept of the publication. MW collected data. KPZ and AB analysed data. KPZ wrote the article. $K Z$ and WAZ critically reviewed the publication. AS and WAZ finally approved it. 